\title{
FONTES DE APOIO SOCIAL A IDOSOS PORTADORES DE DOENÇA PULMONAR OBSTRUTIVA CRÔNICA
}

\author{
Danyelle Almeida de Andrade* \\ Maria do Carmo Eulálio \\ Rômulo Lustosa Pimenteira de Melo"
}

\begin{abstract}
RESUMO. Este trabalho objetivou identificar e estimular fontes de apoio social a idosos portadores de doença pulmonar obstrutiva crônica. Pautado por uma análise qualitativa e com caráter intervencionista, foi realizado através de quatro oficinas, que foram gravadas e posteriormente transformadas em corpus de discursos submetidos à análise categorial temática de conteúdo. A amostra foi composta por sete idosos (seis homens e uma mulher) com média de idade de 70 anos. As temáticas mais recorrentes foram: queixas advindas das limitações impostas pela doença, isolamento e dependência funcional e estímulo das fontes de apoio social. Apesar de a família e os médicos terem sido identificados como as principais fontes de apoio, as dificuldades acarretadas pela enfermidade e o sentimento de incapacidade dificultavam as relações com os familiares e/ou cuidadores e o estabelecimento de novas redes sociais. As oficinas proporcionaram trocas de experiências entre os idosos, desenvolvendo vínculos e promovendo apoio social.
\end{abstract}

Palavras-chave: Idosos; doenças crônicas; grupos de apoio.

\section{SOURCES OF SOCIAL SUPPORT IN ELDERLY HAVING CHRONIC OBSTRUCTIVE PULMONARY DISEASE}

\begin{abstract}
This paper aimed to identify and stimulate social support sources in elderly having Chronic Obstructive Pulmonary Disease. Guided by a qualitative analysis and with interventionist character, it was realized through four workshops which were recorded and later transformed into corpus of speeches submitted to thematic categorical content analysis. The sample was composed by seven elderly (six men and one woman), with mean age of 70 years. The most recurrent themes were: complaints arising from the limitations imposed by the disease, isolation and functional dependency and encouraging sources of social support. Although family and doctors have been identified as the main support sources, difficulties established by the illness and the feeling of incapacity complicated the relation with the family and/or caregivers, as well as for the establishment of new social nets. The workshops provided exchange of experiences among the participants, developing bonds and promoting social support.
\end{abstract}

Key words: Aged; chronic illness; support groups.

\section{FUENTES DE APOYO SOCIAL EN MAYORES PORTADORES DE ENFERMIDAD PULMONAR OBSTRUCTIVA CRÔNICA}

RESUMEN. Este trabajo ha objetivado identificar y estimular fuentes de apoyo social a personas mayores portadores de DPOC. Pautándose en un análisis cualitativo e intervencionista, esta investigación se realizó a través de cuatro talleres que fueron grabados y posteriormente transformados en corpus de discursos sometidos al análisis categorial temático de contenido. La amuestra fue compuesta por siete personas mayores, seis hombres y una mujer. Fueron tres las temáticas más recurrentes en los talleres: quejas por las limitaciones impuestas por la enfermedad, aislamiento y dependencia funcional y estímulo/ampliación de las fuentes de apoyo social del grupo. La familia, las esposas, y los médicos fueron identificados como principales fuentes de apoyo. Las limitaciones impuestas por la enfermedad y el sentimiento de incapacidad dificultan las relaciones con familiares y/o cuidadores y el establecimiento de nuevas redes sociales. Los talleres proporcionaron intercambio de experiencias entre los mayores, desarrollando vínculos y promoviendo apoyo social.

Palabras-clave: Adultos mayores; enfermedades crónicas; grupos de autoayuda.

Mestranda em Psicologia pela Universidade Federal de Pernambuco, Recife-PE.

\# Doutora em Psicopatologia Clínica pela Université Paul Valéry, França. Professora Doutora nível D, Universidade Estadual da Paraíba, Brasil.

^ Mestrando em Psicologia Social pela Universidade Federal da Paraíba, João Pessoa-PB. 
O processo de envelhecimento populacional nos países desenvolvidos acontece de modo paulatino, acompanhado de eficazes políticas públicas de saúde, habitação, trabalho e alimentação; mas nos países em desenvolvimento, entre eles o Brasil, esse processo ocorre subitamente e num contexto cujas condições estruturais não atendem às demandas do novo grupo etário emergente. A precariedade de acesso aos serviços de saúde, a insuficiência e má distribuição dos recursos financeiros, em conjunto com políticas públicas ineficazes, matizam o cenário social desses países (Palloni \& Peláez, 2003).

Ao mesmo tempo em que aumenta a sobrevida da população, verifica-se um crescente número de casos de doenças crônicas, entre as quais se destaca a doença pulmonar obstrutiva crônica (DPOC). A DPOC é considerada uma enfermidade crônica que surge normalmente após os 40 anos de idade, com progressão lenta e irreversível, e está associada à inalação de partículas ou gases nocivos (Seemungal, Hurst \& Wedzicha, 2009). É caracterizada por uma progressiva obstrução do fluxo aéreo que não pode ser revertida completamente e apresenta sintomas crônicos, como tosse, produção de escarro, dispneia aos esforços ou em repouso, intolerância ao exercício e infecções respiratórias. Os pacientes podem também apresentar sintomas sistêmicos e condições de comorbidade, como perda do tônus muscular, perda de peso, doenças cardiovasculares, osteoporose, hipertensão, depressão, distúrbios do sono, declínio cognitivo, disfunções sexuais e possibilidade de diabetes (Fabbri, Luppi, Beghe \& Rabe, 2011).

Entre as consequências dessa patologia destacam-se: maior tempo de internação hospitalar, recuperação lenta, grande frequência de reinternações e invalidez, que se refletem em maiores gastos com os sistemas de saúde (Fabbri, Luppi, Beghe \& Rabe, 2011). As limitações progressivas impostas pela doença, além de dificultarem a realização de atividades básicas da vida diária (ABVD) (Pessoa, Costa, Velloso, Mancuzo, Reis, Parreira, 2012), também dificultam o estabelecimento e manutenção de relações sociais, deixando o idoso cada vez mais isolado e vulnerável a problemas de saúde, como ansiedade e distúrbios cognitivos (Mangueira, Viega, Mangueira, Pinheiro \& Costa 2009). Dessa forma, a estimulação de novas redes de apoio social é vista como um importante recurso para a manutenção e melhora da saúde e qualidade de vida dos idosos (Coventry, Gemmell \& Todd, 2011), pois boas relações interpessoais têm um presumível efeito no enfrentamento de perturbações orgânicas e psicológicas como depressão e doenças coronárias (Thiengo, Santos, Mason, Abelha \& Lovisi, 2011; Abreu-Rodrigues \& Seidl, 2008).

O apoio social pode ser compreendido como o conjunto hierarquizado de sujeitos que cultivam entre si vínculos típicos das relações de dar e receber (Neri, 2005). Esse conjunto de pessoas está presente ao longo de toda a vida e sua presença ou ausência afetam diferentemente a saúde dos indivíduos (Fuster, 2011). Segundo Neri (2005), as fontes de apoio social podem ser categorizadas a partir de alguns aspectos, como propriedades estruturais (tamanho, estabilidade, complexidade, etc.), natureza das relações (formais ou informais, envolvendo amigos ou familiares) e graus de desejabilidade (como livres ou compulsatorias, agradáveis ou desagradáveis). Além dessas categorias, existe ainda a classificação por tipos de apoio social, baseada nos estilos de interação que eles proporcionam, a saber, apoio emocional, apoio informacional e apoio instrumental (Barrón, 1996).

Para o apoio social ser efetivo o sujeito tem que perceber esta relação como favorável ao próprio crescimento, ao bem-estar e à realização de suas próprias metas, demonstrando, assim, o intermédio subjetivo desse conceito. Entre os numerosos fatores inerentes a esse processo perceptivo destaca-se a relação entre o momento vivido pelo sujeito e a fonte de apoio social (família, amigos ou profissionais). Assim, as mesmas ações podem ser percebidas de formas diferentes - por exemplo, uma orientação sobre saúde pode ser percebida como apoio se procede de um médico, mas pode ser desconsiderada se proveniente de um amigo ou de um parente (Fuster, 2011).

A literatura sobre apoio social na velhice destaca que a relação de amizade entre sujeitos da mesma idade é particularmente benéfica, pois são mais funcionais para 0 atendimento das necessidades afetivas dos envolvidos. Entende-se que a troca e o compartilhamento de experiências de vida, necessidades, valores e significados comuns a esses sujeitos contribuem de forma decisiva para a promoção e percepção de suporte social (Neri, 2005).

Assim, considerando a dificuldade de tratamento para os portadores de DPOC e a importância de relações sociais que resultem em apoio, este trabalho teve como objetivo identificar e estimular fontes de apoio social a idosos portadores de DPOC. 


\section{MÉTODO}

\section{Tipo de investigação}

O estudo é de caráter transversal e de cunho qualitativo e abordagem intervencionista.

\section{Participantes}

Participaram deste estudo pessoas com idade igual ou superior a 60 anos, idade a partir da qual uma pessoa é considerada idosa (Organização das Nações Unidas, 2003). Para o trabalho com oficinas foram convidadas 23 pessoas portadoras do diagnóstico de DPOC, residentes na cidade de Campina Grande (PB) e vinculadas a um programa de reabilitação pulmonar desenvolvido na ClínicaEscola de Fisioterapia da Universidade Estadual da Paraíba (UEPB). Para tanto, os idosos necessitavam estar clinicamente estabilizados e disponíveis para participar dos encontros, que aconteceram na Universidade. Ao final, sete idosos aceitaram espontaneamente o convite e não houve desistência. Dos que não aceitaram o convite, as justificativas mais frequentes foram não ter interesse (9) e não possuir expedientes disponíveis, em virtude de outros compromissos (7).

\section{PROCEDIMENTOS}

O presente trabalho foi realizado através de quatro oficinas, desenvolvidas entre os meses de junho e julho de 2009, as quais abordavam, principalmente, a temática do apoio social. Os encontros ocorreram duas vezes por semana; tiveram duração média de três horas e contaram com um intervalo de 20 minutos, destinado a um lanche coletivo.

O recurso das oficinas como uma estratégia metodológica, embora não seja ainda algo muito frequentemente relatado, vem sendo trabalhado como um modelo válido para a intervenção no que diz respeito a questões de saúde. Pretende-se, através de uma construção coletiva de conhecimentos, divulgar e reforçar estratégias que contribuam para a promoção da saúde e da qualidade de vida dos idosos (Almeida, Beger \& Watanabe, 2007). A escolha desta metodologia também almeja concorrer para o aumento de trabalhos que apontem perspectivas saudáveis e aplicáveis ao cenário de envelhecimento populacional (Souza, Santana, Sá \& Robers, 2009).

As Oficinas tiveram como foco central a forma como cada idoso portador de DPOC experienciava e enfrentava sua doença, como aderiram ao tratamento e como eram as suas relações e fontes de apoio social. A finalidade residiu na criação de um espaço de reflexão e de trocas de experiências que pudessem propiciar novas formas de saberes, construídas a partir do contexto próprio do grupo, entendendo-se que essas relações e trocas de experiências seriam importantes para o surgimento de fontes de apoio.

Contou-se com um planejamento de atividades pertinente ao objetivo da pesquisa, resultando em um roteiro semiestruturado para a condução de cada encontro. De forma resumida, a estruturação se encontra esquematizada no quadro abaixo.

\begin{tabular}{|c|c|c|c|c|}
\hline \multicolumn{5}{|c|}{ Estruturação dos encontros } \\
\hline & 1a Oficina & $2^{\mathrm{a}}$ Oficina & 3a Oficina & 4a Oficina \\
\hline & Formação de vínculo no grupo & $\begin{array}{l}\text { O sujeito, a doença e seus } \\
\text { desdobramentos }\end{array}$ & $\begin{array}{l}\text { A doença, o doente, a adesão } \\
\text { ao tratamento e apoio social }\end{array}$ & $\begin{array}{l}\text { Qualidade de vida e o apoio } \\
\text { social }\end{array}$ \\
\hline Introdução & $\begin{array}{l}\text { Esclarecimento sobre o trabalho } \\
\text { das Oficinas; Relaxamento; }\end{array}$ & Resgate do encontro anterior; & Resgate do encontro anterior; & $\begin{array}{l}\text { Resgate do encontro } \\
\text { anterior; }\end{array}$ \\
\hline Atividades & $\begin{array}{l}\text { Reflexão corporal acerca das } \\
\text { regiões que doem ou } \\
\text { incomodam (objetivo de elaborar } \\
\text { formas de enfrentar as } \\
\text { limitações e de compartilhar } \\
\text { experiências semelhantes). }\end{array}$ & $\begin{array}{l}\text { Atividade lúdica: recortes de } \\
\text { revistas para investigar as } \\
\text { representações e imagens } \\
\text { associadas à DPOC e sua } \\
\text { relação com as fontes de } \\
\text { apoio social. }\end{array}$ & $\begin{array}{l}\text { Roda de conversa sobre a } \\
\text { DPOC e seu histórico pessoal } \\
\text { (eventos de crises, relações } \\
\text { interpessoais, diagnóstico, } \\
\text { limitações); }\end{array}$ & $\begin{array}{l}\text { Esclarecimentos sobre a } \\
\text { DPOC; Roda de conversa } \\
\text { sobre autoestima, } \\
\text { enfrentamento e apoio } \\
\text { social; }\end{array}$ \\
\hline Lanche coletivo & \multicolumn{4}{|c|}{ Adjacente ao lanche eram fornecidas informações para uma alimentação saudável. } \\
\hline \multirow{3}{*}{$\begin{array}{l}\text { Atividades e } \\
\text { encerramento do } \\
\text { trabalho }\end{array}$} & \multirow{3}{*}{$\begin{array}{l}\text { Roda de conversa sobre boas } \\
\text { lembranças e experiências } \\
\text { pessoais; História pessoal do } \\
\text { nome próprio. }\end{array}$} & \multirow[t]{3}{*}{$\begin{array}{l}\text { Roda de conversa sobre a } \\
\text { atividade lúdica. }\end{array}$} & \multirow{3}{*}{$\begin{array}{l}\text { Roda de conversa sobre } \\
\text { autopercepção das relações } \\
\text { interpessoais e a presença ou } \\
\text { ausência de apoio; } \\
\text { Atividade lúdica: brincando com } \\
\text { provérbios e seus sentidos; } \\
\text { Relaxamento. }\end{array}$} & $\begin{array}{l}\text { Atividade lúdica: brincando } \\
\text { de caça palavras; }\end{array}$ \\
\hline & & & & Exibição de um vídeo \\
\hline & & & & $\begin{array}{l}\text { falas de todos os encontros } \\
\text { (roda de conversa). }\end{array}$ \\
\hline
\end{tabular}


Alguns enfoques foram comuns a todos os encontros, como: orientações sobre a saúde referentes às informações acerca da doença crônica (DPOC), estimulação da cognição, reflexão sobre os sentimentos e afetividade dos participantes, estimulação da comunicação interpessoal e, principalmente, estimulação de novas fontes de apoio social, procurando-se favorecer novas formas de enfrentar os eventos decorrentes da DPOC. A isso se acrescenta que a organização e ornamentação da sala eram modificadas após cada Oficina e se perguntava aos idosos quais as diferenças da sala entre os encontros, com o objetivo de estimular a atenção e memória.

Para a coleta de dados lançou-se mão de um aparelho de áudio, de um questionário demográfico e de apontamentos advindos das observações participantes. Participaram, ainda, três facilitadores (dois alunos de Psicologia, um do sexo masculino e um do sexo feminino) e uma professora psicóloga. Adotou-se como prérequisito para este trabalho a participação em um treinamento para o desenvolvimento dos encontros, oportunizando aos facilitadores a familiarização com a metodologia e aptidão para sua aplicação.

\section{Análise dos dados}

Foi utilizada como estratégia de análise a discussão de posturas, sentimentos e comportamentos diante das situações propostas, com atuação direta ou indireta na promoção da saúde e hábitos saudáveis de vida dos participantes. Durante os encontros todos os participantes tiveram oportunidade de expor suas ideias, sendo com isso estimulado o convívio em grupo, para que suas relações interpessoais pudessem atuar como agente mútuo de tratamento e se tornassem também fonte de apoio social. Os encontros foram audiogravados e depois transcritos e transformados em corpus de discursos que, por sua vez, foram submetidos à análise categorial temática de conteúdo. Esta técnica se divide em três etapas: 1) a préanálise; 2) a exploração do material; e 3) o tratamento dos resultados, a inferência e interpretação (Bardin, 2011).

O questionário demográfico foi composto de perguntas relativas a dados como idade, escolaridade e renda familiar, tendo por finalidade caracterizar a amostra e obter informações objetivas e descritivas a respeito dos participantes. Para isto, seus dados foram analisados à luz da estatística descritiva. O registro da observação participante se embasa naquilo que não é falado, mas visto e captado pelo observador. Esta ferramenta auxiliou na construção deste artigo, na medida em que o registro das impressões e sentimentos dos facilitadores foi utilizado para relacionar os acontecimentos às suas representações e para desvendar as contradições entre as normas, regras e práticas da vida cotidiana do grupo (Minayo, 2007).

\section{Considerações éticas}

Este estudo foi submetido às normas do Conselho Nacional de Saúde e obteve aprovação do Comitê de Ética em Pesquisa da Universidade Estadual da Paraíba (CAAE 0063.0.133.000-09 em 06/04/2009). Todos os idosos que participaram do estudo foram informados do objetivo da pesquisa e do sigilo das informações coletadas. Após os esclarecimentos pertinentes ao trabalho, cada participante foi solicitado a ler ou a escutar a leitura detalhada do Termo de Consentimento Livre e Esclarecido e a assiná-lo, caso concordasse em participar da pesquisa.

\section{RESULTADOS E DISCUSSÃO}

Os seis homens que participaram desta pesquisa apresentaram média de idade de 71 anos (DP $=11,86)$, e a mulher tinha 68 anos de idade. A prevalência de homens se mostra contraditória com o fenômeno conhecido como feminização da velhice (Neri, 2007). Esse fenômeno justifica a prevalência do sexo feminino entre idosos, devida, entre outros fatores, à expectativa de vida mais elevada para as mulheres. Não obstante, quando o olhar se volta para as especificidades do grupo em questão, percebe-se que 0 ato de fumar foi $e$ ainda é predominantemente masculino, como comprovado em estudos que observaram, direta ou indiretamente, os índices do tabagismo quanto ao sexo (Goulart et al., 2010). Nestes estudos, aponta-se uma relação significativa entre longos períodos do uso de cigarro e a instauração da enfermidade crônica, havendo também a possibilidade desta ser acarretada por complicações de outras enfermidades. Os homens idosos do presente estudo tiveram uma relação direta com o uso do tabaco por muitos 
anos, atingindo uma média de 31 anos (Dp \pm 12).

No que se refere ao estado civil, três dos homens eram casados e três viúvos, e a mulher era divorciada. No tocante à remuneração, quatro participantes recebem até um salário mínimo (entre eles a mulher), dois recebem entre um e três salários e um recebe entre três e cinco salários mínimos (salário mínimo vigente igual a $R \$ 465,00)$. Quanto à escolaridade, cinco possuíam o Ensino Fundamental I incompleto e dois não tinham escolaridade (inclusive a idosa).

\section{Oficinas e apoio social}

Os resultados desta pesquisa serão apresentados de forma hierárquica, no intuito de responder ao objetivo da pesquisa. Sendo assim, com base na categorização dos conteúdos das oficinas, inicialmente buscou-se identificar as fontes de apoio social (Fontes de apoio social dos idosos). Como consequência da DPOC e das fontes de apoio social, será apresentado, em seguida, um tópico referente à dependência e isolamento social, e, por último, as possíveis formas de apoio desenvolvidas durante as oficinas (Estímulo das fontes de apoio social).

Os fragmentos de discursos dos participantes estão identificados através de uma numeração de 1 a 7 do sexo ("H" para homens e "M" para a mulher) e da idade correspondente. As falas dos participantes foram transcritas de forma integral, sem correção gramatical.

\section{Fontes de apoio social dos idosos}

Santos e Pavarini (2010), em pesquisa desenvolvida no Rio Grande Sul (Brasil), descreve que a família é a fonte primária de apoio social do idoso e, dentro da família, as mulheres são as maiores provedoras de cuidado. Esse fato parece ter se replicado no presente estudo, pois nos discursos dos participantes sobre as pessoas de quem mais gostam, em quem confiam e de quem recebem cuidados, destacou-se a família, mais especificamente, a figura feminina. Para Lemos e Medeiros (2006), embora esteja cada vez mais inserida no mercado de trabalho, a mulher continua assumindo a maior responsabilidade do cuidado de idosos fragilizados e dependentes. Perracini e Neri (2006) identificam que existe uma expectativa social de que a atividade do cuidar seja naturalmente feminina e que, mesmo com as mudanças sociais advindas da modernidade (como o ingresso da mulher no mercado de trabalho), esta expectativa ainda persiste (Amedola, Oliveira \& Alvarenga, 2008). Corroborando esta ideia, um participante diz: "Depois de mim, eu tenho uma irmã. Depois dela, é minha família, que eu tenho, meus filhos, meus netos, entendeu? Eu sei que posso confiar neles" (Part.7, H, 60 anos). Outros compartilham da temática:

\begin{abstract}
"Eu tenho uma filha mais velha, ela é a mais "assim"; a outra tem uma natureza mais fechada um pouco. Mas (a filha mais velha) é mais carinhosa, mais aberta... Eu acho que confio mais nela pra resolver as coisas, acho que ela puxou a mim." (Part. 1, H, 60 anos)

"A única solução que eu tenho é meu telefonezinho! Quando eu fico preocupado telefono pra minha filha, ela vem; às vezes quando é um problema que eu tenho que resolver e não posso resolver sozinho eu ligo pra ela e ela vem, resolve comigo. (...)" (Part. 3, H, 66 anos)
\end{abstract}

Outra fonte de apoio social frequentemente citada pelos idosos foi o cuidado dos médicos que acompanham a DPOC, demonstrando, em seus discursos, admiração, agradecimento e confiança. "Eu acho assim que a melhor coisa que existe no mundo, primeiramente é Deus, que tá sobre nossa cabeça; mas se não fosse o médico, como que a gente estaria no mundo?" (Part. 2, H, 86 anos); "Eu adoro a minha doutora, agradeço a Deus por ela tomar conta de mim." (Part. 5, M, 68 anos). Esta fonte de apoio social pode ser entendida como apoio instrumental, pois compreende o cuidado na prestação de serviços (Barrón, 1996).

Os idosos parecem, assim, apresentar dois tipos de apoio social: um ligado ao apoio da família, mais especificamente, à figura feminina - portanto, apoio emocional; e o outro relacionado aos responsáveis pelos cuidados médicos, caracterizando-se como apoio instrumental. Durante as oficinas percebeu-se a ausência de formas de apoio ligadas aos amigos, conforme é discutido no próximo tema. $O$ isolamento social vivenciado pelos idosos pode dificultar a manutenção e 0 estabelecimento de novas redes sociais.

\section{Dependência e isolamento social}

A DPOC tem por característica mais sensível uma dificuldade na respiração que acaba por 
limitar, a depender do estadiamento (nível atual da doença - leve, moderado, grave), a autonomia para realizar diversas atividades. Pode comprometer desde um simples banho até uma caminhada (Fabbri, Luppi, Beghe \& Rabe, 2011). Este comprometimento da capacidade funcional tem implicações importantes para a família, que tenta dar apoio para diminuir as limitações do idoso; mas tal atitude pode ser também percebida pelo idoso como uma ampliação de sua incapacidade, diminuindo sua autoestima e dificultando sua percepção de apoio social. Essas limitações interferem até na possibilidade de estabelecer novas redes sociais, na medida em que sua capacidade de contato social é reduzida. Identifica-se isso quando os participantes dizem: "Eu podia andar, sair, pegar o ônibus só, e agora ninguém deixa eu fazer mais nada!" (Part. 3, H, 88 anos); "Eu lembro que sou doente quando eu vejo o pessoal comendo alguma coisa. Chega vem água na boca, e pega e diz que eu não posso comer por que sou doente; aí chega enche de lagrima $o$ olho." (Part. 1, H, 60 anos)

Muitas vezes o cuidador é submetido a situações de extremo desgaste, tanto físico como emocional (Garbin, Sumida, Moimaz, Prado \& Silva, 2010), pois frequentemente ele é colocado pelo idoso no lugar de responsável pelo seu isolamento social. Neste sentido, as redes formais de apoio social poderiam contribuir significativamente; mas no Brasil essas estruturas ainda se mostram incipientes e não constituem uma rede de apoio organizada, o que revela a inexistência de políticas sociais que proporcionem suporte às famílias e aos cuidadores de idosos fragilizados. Dessa forma, o cuidador trabalha sobrecarregado, pois não conta com as orientações pertinentes às necessidades do idoso (Barros, Oliveira Neto, Silva, Silva, \& Silva 2010).

As conversas dos facilitadores objetivaram a construção, por parte dos idosos, da necessidade de adaptar tarefas para se adequarem às suas limitações (a depender de cada caso), como, por exemplo, tomar banho sentado, não se abaixar para amarrar os sapatos, dar preferência a calçados sem cadarços, mostrando que essas adaptações poderiam torná-los menos dependentes.

Para os idosos, o sentimento de estar dependente - seja de outras pessoas seja de aparelhos e remédios - é um desafio. Este desafio provoca respostas que diferem de indivíduo para indivíduo conforme suas influências ambientais. As características de personalidade, os recursos existentes para atender à dependência, as características do suporte social e o significado da dependência para o próprio indivíduo são fatores que podem interferir na forma como se percebe o apoio oferecido e como se responde à dependência (Lemos \& Medeiros, 2006).

$O$ cuidado e a ajuda devem ser oferecidos no sentido de minimizar sua dependência e potencializar suas capacidades (Barros et al., 2010). Lemos e Medeiros (2006) colocam que o fato de o idoso saber que pode controlar 0 ambiente tem um efeito benéfico sobre seu bemestar. Familiares, cuidadores e profissionais devem pensar em como oferecer ao idoso a ajuda necessária, em vez de fazer por ele.

Os idosos também relataram outros problemas, referentes a outras patologias, ou até mesmo decorrentes do processo de envelhecimento, que terminam por potencializar ainda mais suas limitações: "Onde mais dói é a coluna, as costas... o que dói mais é as costas, fica ruim até para tocar sanfona" (Part.7, H, 60 anos); "As dores nas costas num deixa eu fazer nada!" (Part. 1, H, 60 anos); "Você já tá conhecendo onde é que dói [risos; referindo-se à perceptível dificuldade de se levantar da cadeira: no joelho!" (Part. 5, M, 68 anos)

Como se verá a seguir, um dos objetivos das ficinas foi o de trabalhar a percepção dos idosos sobre sua saúde e, dessa forma, fazê-los refletir não apenas sobre suas limitações, mas também sobre suas capacidades e possibilidades para realizar atividades.

\section{Estímulo e ampliação das fontes de apoio social}

As atividades realizadas para este estudo, e até as conversas mais informais, estavam permeadas por temas relacionados à educação em saúde e a mudanças no estilo de vida, acreditando-se que este seria um dos caminhos para promover apoio. Para isso, eram propostas atividades e debates que estimulassem a reflexão sobre suas condições de vida. Os facilitadores utilizavam essas conversas para esclarecer algumas dúvidas levantadas pelos participantes das Oficinas. Tratava-se de um processo de constantes trocas e de construções de conhecimentos, como propõe o trabalho com esse tipo de técnica.

Baseados na perspectiva da Psicologia Positiva (área da Psicologia que busca os 
aspectos salutogênicos dos seres humanos), os facilitadores intervinham nos diálogos de forma a explorar alternativas para o cotidiano antes não pensadas. Essa perspectiva de desenvolvimento poderia propiciar uma abertura para o que há de positivo e saudável no ser humano (Keyes \& Haidt, 2003), direcionando a atenção dos idosos não apenas para as limitações da doença, mas, sobretudo, para as capacidades que possuíam. Buscou-se proporcionar novas formas de enfrentamento, enfatizando-se características positivas como esperança, criatividade, coragem, sabedoria e felicidade, pois, assim, segundo Paludo e Koller (2007), contribui-se com o desenvolvimento e funcionamento saudável das pessoas, preocupando-se com o fortalecimento das competências em vez de apenas trabalhar com as deficiências.

Part.3: "- As pessoas costumam me perguntar: "Como é que vai?". Eu digo: "Me pergunte onde é que dói"."

Facilitadora: "- Mas, de repente, eu poderia perguntar: onde é que não dói?'

Part.3: "- Eu num sei dizer não, acho que os braços... (reflexivo)

Facilitadora: - Pois é. Ouvindo eu sei que o senhor tá! Tá falando, tá me vendo..."

Part.3: "- É né. Tem hora que a gente esquece dessas coisas. Acho que para a idade tá bom demais (risos)."

Admite-se que algumas limitações impostas pela patologia não podem ser superadas, mas acredita-se que aspectos como os citados acima (esperança, criatividade, coragem, sabedoria e felicidade) possam atuar no sentido de diminuir os efeitos da dependência sobre a qualidade de vida (Paludo \& Koller, 2007).

Sabendo-se que a dependência e o isolamento social vivenciados pelos idosos em questão podem levar a uma diminuição de estímulos cognitivos, entende-se que isso dificultaria o estabelecimento e a manutenção de novas redes de apoio (Abreu \& Tamai, 2006). Estudos também demonstram que a depressão é comum nos casos de portadores de DPOC e que, desta forma, também pode vir a ser outro fator a afetar a cognição dos indivíduos (Senger, 2006). Assim, todos os encontros foram permeados por diversas formas de estímulo à cognição dos participantes, dando-se maior ênfase à memória e à atenção, a exemplo da decoração da sala, que era mudada a cada encontro, buscando-se estimular sua observação e criar novos estímulos de atenção.

Foi confeccionado um mural intitulado Memória do Grupo, que expunha fotos e frases do encontro anterior. Com esse instrumento procurou-se instigar o interesse dos idosos, estimulando lembranças das atividades e encontros passados. Os idosos, dessa forma, reconheciam-se no mural, criando, através de um sentimento de pertença, uma identificação com o grupo. Esse mural despertava a curiosidade deles, por estarem se vendo nas fotos e por perceberem o zelo com que eram produzidas as oficinas. Isso pode ser observado em algumas falas: "Olha ali o que vocês fizeram no encontro passado. Foram colando e foram conversando, se conhecendo" (Estímulo da facilitadora); "Eu me vi, vi a minha bengala [risos] (...) Eu tava conversando com uma dessas meninas, eu consigo lembrar da gente" (Part. 3, $\mathrm{H}, 88$ anos); "Eu tava colado nessa hora" [risos] (Part.1, H, 60 anos); "Eu não sei se fui eu que falei não [referindo-se às frases expostas], mas eu acho que foi, porque falar em mulher é comigo mesmo, né! [risos]" (Part. 3, H, 88 anos)

Durante a pesquisa observou-se que as redes sociais do grupo estavam promovendo comportamentos de cuidado entre os participantes - por exemplo, quando um dos idosos participantes chega atrasado, imediatamente um dos seus colegas expressa que o grupo estava pensando nele. Em seguida, outro participante expressa sua preocupação: "Estávamos pensando em você ainda agorinha." (Part.1, H, 60 anos); "Deu gripe, mestre?" (Part. 2, $\mathrm{H}, 86$ anos)

Este sentimento de preocupação e atenção de uns com os outros atua no sentido de aumentar a autoestima e o bem-estar de cada idoso (Uchino, 2004), tendo em vista que estas relações são ainda mais significativas quando existe alguma característica em comum que una o grupo (Fuster, 2011), como no caso deste trabalho, em que o grupo foi formado por idosos portadores de uma mesma patologia.

Durante os encontros sempre houve a tentativa de reconstruir algumas ideias ou de modificar a forma de pensar a doença, pois com isso os participantes poderiam assumir um caráter mais ativo ao enfrentá-la (Selli, Meneghel, Junges \& Vial, 2008). Por vezes essa 
postura partia do próprio grupo, como quando um participante diz: "Eu posso morrer, mas não me acostumo com a doença!" (Part. 2, H, 86 anos). Nesse momento outro participante lhe responde: "Eu acho, do meu ponto de vista, assim (...) a gente não pode arrancar a doença! A gente tem que procurar melhorar um pouco, procurar tratamento, e procurar não se aperrear tanto, né?" (Part. 5, M, 68 anos).

Dessa forma, estas novas fontes informais de apoio assumem um papel importante, pois quando se trata de pessoas que passam por dificuldades semelhantes, o potencial estigmatizante é menor. Fuster (2011) afirma que estas formas de apoio tendem a prejudicar menos os sentimentos de competência e controle sobre suas próprias vidas, pois com a família e com os amigos se estabelecem relações baseadas mais na estima e na reciprocidade do que na autoridade e unidirecionalidade.

\section{CONSIDERAÇÕES FINAIS}

Os facilitadores desta pesquisa atuaram no sentido de promover e estimular apoio social, criando um ambiente onde os participantes pudessem compartilhar os mesmos tipos de problemas e receber um apoio que os ajudasse a enfrentar seus próprios problemas. Ao mesmo tempo, buscou-se estimular e promover bons hábitos de vida e saúde. As principais fontes de apoio observadas advieram da família, com destaque para a figura feminina, e dos médicos que tratavam da DPOC. Percebeu-se que a incapacidade funcional gerada pela doença afasta os portadores de hábitos sociais, diminuindo a possibilidade de estabelecer novas redes de apoio. Talvez por isso não foram observadas fontes provenientes de amizades e/ou grupos de convivência de idosos. Durante as oficinas os participantes expressaram sentimentos mútuos de preocupação e cuidados, fato que pode indicar desenvolvimento de novas fontes de apoio entre eles. Por este motivo, salienta-se que esta técnica pode ser utilizada como forma de estimular novas fontes de apoio para acometidos de DPOC em programas de reabilitação pulmonar.

Considerando-se as limitações impostas pela doença, a participação de idosos portadores de DPOC constitui-se em uma dificuldade inerente a esse tipo de pesquisa. Ainda assim, o tamanho do grupo parece ter possibilitado a expressão de sentimentos e experiências pessoais. Não obstante, acredita-se que 0 trabalho em grupo não deva se restringir a esse número, podendo ser realizadas atividades com grupos maiores. Sugere-se a replicação dessa técnica em centros de tratamento especializados onde exista maior número de pacientes. Esses locais, através de um acompanhamento, também poderiam apresentar maior capacidade de entender como essas novas fontes de apoio poderiam atuar na saúde a longo prazo.

Seria enriquecedor investigar os processos de resiliência, o sentido de vida e as estratégias de enfrentamento utilizadas pelos idosos, pois ajudariam a entender de que forma eles enfrentam e respondem aos desafios impostos pela DPOC, fomentando novos programas de intervenção que objetivassem não apenas 0 controle dos sintomas físicos, mas também a melhoria da saúde mental. Para futuras pesquisas, sugere-se ainda inserir os familiares responsáveis pelos cuidados aos idosos em oficinas, com o objetivo de oferecer meios de aquirir conhecimento acerca de como viver e conviver melhor com os portadores de DPOC. Para tanto, poderiam ser realizadas oficinas apenas com os familiares, e posteriormente inseri-los em alguns encontros com os idosos, objetivando à melhoria da qualidade do apoio oferecido pelo familiar.

\section{REFERÊNCIAS}

Abreu, V. P. S., \& Tamai, S. A. B. (2006). Reabilitação cognitiva em gerontologia. In: Freitas, E. V., Py, V., Cançado, F. A. X., Doll, J., \& Gorzoni, M. L. Tratado de geriatria e gerontologia. Rio de Janeiro: Guanabara Koogam.

Abreu-Rodrigues, M., \& Seidl, E. M. F. (2008). A importância do apoio social em pacientes coronarianos. Paidéia, 18(40), 279-288.

Almeida, M. H. M., Beger, M. L. M., \& Watanabe, H. A. W. (2007). Oficina de memória para idosos: estratégia para promoção da saúde. Interface - Comunicação, Saúde, Educação, 22(11), 271-280.

Amendola, F., Oliveira, M. A. C., \& Alvarenga, M. R. M. (2008) Qualidade de vida dos cuidadores de pacientes dependentes no programa de saúde da família. Revista Texto \& Contexto-Enfermagem, 17(2), 266-272.

Bardin, L. (2011). Análise de conteúdo. São Paulo: Edições 70.

Barrón, A. I. (1996). Apoyo social: aspectos teóricos y aplicaciones. Madrid: España Editores. 
Barros, J. D., Oliveira Neto, J. M., Silva, S. L. B., Silva, R. S., \& Silva, M. F. P. (2010). Percepção e expectativas de cuidadores no processo saúde/doença na pessoa idosa. Revista Saúde, 4(2), 28-36.

Coventry, P. A., Gemmell, I. and Todd, C. J. (2011). Psychosocial risk factors for hospital readmission in COPD patients on early discharge services: a cohort study. BMC Pulmonary Medicine, 11(49).

Fabbri, L. M., Luppi, F., Beghe, B., \& Rabe, K. F. (2011) The Multiply Components of COPD. In: Hanania, N. A., Sharafkhaneh, A. (Ed.) COPD - A Guide to Diagnosis and Clinical Management (pp. 1-20), New York: Humana Press.

Fuster, E. G. (2011). Apoyo social e intervención social y comunitaria. In: Sedano, I. F., Domínguez, J. F. M., \& Alonso, F. M. Psicología de la Intervención Comunitaria. Editora Desclée de Brouwer Bruges: Bélgica.

Garbin, C. A. S., Sumida, D. H., Moimaz, S. A. S., Prado, R. L., \& Silva M. M. (2010) O envelhecimento na perspectiva do cuidador de idosos. Ciência \& Saúde Coletiva, 15(6), 2941-2948.

Goulart, D., Engroff, P., Ely, L. S., Sgnaolin, V, Santos, E. F., Terra, N. L., \& De Carli, G. A. (2010) Tabagismo em idosos. Revista Brasileira de Geriatria e Gerontologia, Rio de Janeiro,13(2), 313-320.

Keyes, C. L. M., \& Haidt, J. (Eds. ). (2003) Flourishing: Positive Psychology and the life well lived. American Psychological Association. Washington, DC.

Lemos, N., \& Medeiros, S. L. (2006) Suporte Social ao idoso dependente. In: Freitas, E. V., Py, V., Cançado, F. A. X., Doll, J., \& Gorzoni, M. L. Tratado de geriatria e gerontologia. Rio de Janeiro: Guanabara Koogam.

Mangueira, N. M., Viega, I. L., Mangueira, M. A., Pinheiro, A. N., \& Costa, M. R. (2009) Correlation between clinical parameters and health-related quality of life in women with COPD. Jornal Brasileiro de Pneumologia, 35(3), 248-255.

Minayo, M. C. (Org) (2007). Pesquisa Social: teoria, método e criatividade. 26 ed., Petrópolis: Vozes.

Neri, A. L. (2005) Palavra-chave em gerontologia. Campinas: Alínea.

Neri, A. L. (2007) Feminização da velhice. In: Neri, A. L. (org). Idosos no Brasil: vivências desafios e expectativas na terceira idade. São Paulo: Perseu Abramo, SESC-SP.

Organização das Nações Unidas (ONU) (2003). Plano de ação internacional sobre o envelhecimento. Brasília: Secretaria Especial dos Direitos Humanos

Palloni, A., \& Peláez, M. (2003) Histórico e natureza do estudo. In: Lebrão, M. L., \& Duarte, Y. A. O. SABE: saúde, bem-estar e envelhecimento. O Projeto SABE no município de São Paulo: uma abordagem inicial. Brasília: Organização Pan-Americana da Saúde, 13-32.

Paludo, S. S., \& Koller, S. H. (2007). Psicologia Positiva: uma nova abordagem para antigas questões. Paidéia, 17(36), 9-20.
Perracini, M. R., \& Neri, A. L. (2006) Tarefas de cuidar: com a palavra, mulheres cuidadoras de idosos de alta permanência. In: Neri, A. L. (org) Cuidar de idosos no contexto da família: questões psicológicas e sociais. Campinas: Alínea Editora.

Pessoa, I. M. B. S., Costa, D., Velloso, M., Mancuzo, E., Reis, M. A. S., Parreira, V. F. (2012). Efeitos da ventilação não-invasiva sobre a hiperinsuflação dinâmica de pacientes com DPOC durante atividade da vida diária com os membros superiores. Revista Brasileira de Fisioterapia, 16(1), 61-67.

Santos, A. A., \& Pavarini, S. C. I. (2010) Perfil dos cuidadores de idosos com alterações cognitivas em diferentes contextos de vulnerabilidade social. Revista Gaúcha de Enfermagem, Porto Alegre, 31(1), 115-122.

Seemungal, T. A., Hurst, J. R., \& Wedzicha, J. A. (2009). Exacerbation rate, health status and mortality in COPD a review of potential interventions. International Journal of Chronic Obstructive Pulmonary Disease, 4, 203-223

Selli, L., Meneghel, S., Junges, J. R., \& Vial. E. A. (2008). O cuidado na ressignificação da vida diante da doença. $O$ Mundo da Saúde São Paulo. 32(1), 85-90.

Senger, J. (2006) Doença Pulmonar Obstrutiva Crônica. In: Freitas, E. V., Py, V., Cançado, F. A. X., Doll, J., \& Gorzoni, M. L. (2006). Tratado de geriatria e gerontologia. Rio de Janeiro: Guanabara Koogam.

Souza, P. A., Santana, R. F., Sá, S. P. C., \& Robers, L. M. V. (2009). Oficinas de estimulação cognitiva para idosos com demência: uma estratégia de cuidado na enfermagem gerontológica. Revista Brasileira de Ciências do Envelhecimento Humano, Passo Fundo, 6(3), 352-372.

Thiengo, D. L., Santos, J. F. C., Mason, V. C., Abelha, L., \& Lovisi,, G. M. (2011). Associação entre apoio social e depressão durante a gestação: uma revisão sistemática. Cadernos de Saúde Coletiva, Rio de Janeiro, 19 (2): 129-138.

Uchino, B. N. (2004) Theoretical Perspectives Linking Social Support to Health Outcomes. In: Uchino, B. N. Social support and physical health:Understanding the Health Consequences of Relationships, Yale University: New Haven and London, 33-54.

Recebido em 22/05/2012 Aceito em 20/10/2012

Endereço para correspondência: Danyelle Almeida de Andrade. Rua Alfredo Farias Pimentel, 68, Bairro Catolé, CEP 58410-675, Campina Grande-PB, Brasil. E-mail: dany.almeidaandrade@hotmail.com. 